\title{
On the Disadvantages of Media as a Service with Regard to Psychological Ownership
}

\author{
Claus-Peter H. Ernst \\ Frankfurt UAS / SRH University Heidelberg \\ cernst@fb3.fra-uas.de
}

\author{
Dirk Weitzel \\ Johannes Gutenberg-Universität Mainz \\ dweitzel@uni-mainz.de
}

\begin{abstract}
Media as a Service (MaaS), which enables customers to access entire media libraries over a subscription period, has become an important revenue driver for the entertainment industry. By using an experiment related to music consumption, our study suggests that MaaS services, and in particular the ones that are free of charge, cause customers to feel a lower degree of psychological ownership (PO) for the provided content than for content provided via physical media and media files. Since PO is known to be an important driver of customers' behaviors and feelings such as their willingness to pay, these findings suggest that PO might hinder MaaS' continuing success.
\end{abstract}

\section{Introduction}

The music and film industry has been struggling with loss of revenue regarding their content due to the development of the web and the associated threat of digital piracy $[10,26,44]$. However, industry executives today place great hopes in media as a service (MaaS) services such as Spotify and Netflix, which are believed to be even more revolutionary than the industry's shift into the download business [27]. Indeed, MaaS, which enables customers to access entire media libraries over a subscription period, is experiencing high growth rates. For example, the latest available global music report [26] shows a growth in paid subscriptions to MaaS services by 176 million users, which led to an annual revenue increase of 41.1 percent in this area. Overall, the share of MaaS on the global music industry revenue now accounts for 38.4 percent.

However, we believe that MaaS still holds challenges for the entertainment industry. Indeed, due to the entertainment industry's growing dependence on the service's revenue, declining success would have negative consequences for all entities involved. We believe that for the content provided by MaaS, customers' psychological ownership (PO) — a "state in which individuals feel as though the target of ownership (material or immaterial in nature) or a piece of it is "theirs"' [39, p. 299]-will be especially important to maintain the industry's success.

In this article, we hypothesize that MaaS services and in particular the ones that are free of charge might, by design, cause customers to feel a lower degree of PO for the provided content than for content provided via physical media and media files. Since PO is known to be an important influence factor of loyalty, willingness to pay, customer satisfaction, word-ofmouth, and service valuation amongst others $[1,20,25$, $28,45,47]$, a lower degree of PO by design could have negative consequences for the entertainment industry as a whole, as well as for the providers of MaaS.

In order to evaluate our hypotheses, we conducted an experiment with a between-subjects design in the context of music consumption. Subjects were randomly assigned to four experimental groups (free music as a service, paid music as a service, files from online media stores, CDs). Next, they were asked to think about and name the music album they most frequently listened to via the respective medium and then answered items from Peck and Shu's well-established PO scale Peck and Shu [33] for the album they had just thought about.

Our findings suggest that the levels of PO that customers have for content on free MaaS services are significantly lower than for content on paid MaaS services. In addition, customers seem to have a significant higher level of PO for content provided via physical media and media files than for content provided via MaaS.

The paper is structured as follows: First, we will introduce the concept of MaaS. Afterwards we will elaborate on the theoretical background of PO including its entities and antecedents. Drawing from this information, we will then outline our hypotheses. Finally, we will present and discuss our results before concluding our article with the limitations of our study and the implications of our findings. 


\section{Theoretical background}

\subsection{Media as a service}

Since the web was created, it has become an expansive worldwide system that people use on a daily basis. Its expansion and widespread use has been aided by steady technical improvements over the years, such as bandwidth increase and advancements in data compression methods. In the face of this rapidlychanging environment, different entertainment industries (e.g., the music, TV and movie industries) have been experiencing particularly intense transformation processes. In particular, media as a service (MaaS) providers such as Netflix and Spotify have gained momentum over the years. They have created multiple challenges to the traditional business models and distribution channels of media companies (such as the sale of physical media or the sale of digital music and video files [e.g., 26]).

MaaS is characterized by its capacity to allow customers to access entire media libraries. More specifically, customers have access to millions of songs, e-books, video games, movies, and TV episodes, and can select whatever they would like to listen to, read, play, or watch during the subscription period. The content is provided to the customer via (1) streaming media, or (2) download media.

Streaming media can be defined as "a method of transmitting or receiving data (especially video or audio material) over a computer network as a steady, continuous flow, allowing playback to start while the rest of the data is still being received" [12]. In other words, the media stream is delivered directly and in real-time from the server of the streaming media service provider to the device of the user without persistent storage of the content on the corresponding device [3]. ${ }^{1}$ In contrast, download media is completely downloaded to and then stored on the customers' respective devices. In other words, downloaded media is not necessarily delivered in real-time and can additionally be listened to, read, played, or watched offline, whereas streaming media cannot.

MaaS has changed large parts of the entertainment market from an ownership-based consumption market to an access-based consumption market. More specifically, instead of "owning" music albums, movies, and TV shows, access-based consumption can

\footnotetext{
${ }^{1}$ Streaming media itself can be divided into live streaming and ondemand streaming [30]. In live streaming, the media content is delivered to one or more users through a live and synchronized feed. In contrast, in on-demand streaming, the media stream is not synchronized, and instead is delivered individually to each user, i.e., a user has the freedom and flexibility to listen to or watch media whenever they want to.
}

be described as a short-term oriented, limited usage of goods which are provided and controlled by a provider's network [40]. Whereas bought content transfers unlimited consumption rights with regard to the number of consumptions and the timeframe of content consumptions [14, 32], access-based consumption is characterized by the temporary transfer of content "ownership" since consumption is limited to the subscription period (and, potentially, by license agreements between the MaaS provider and the contents' copyright owner). In other words, accessbased consumption can be seen as an alternate approach to the long-term oriented interaction of goods in the ownership-based consumption, where "[i]nstead of buying and owning things, ... consumers prefer to pay for the experience of temporarily accessing them" [5, p. 881]. With this regard, MaaS, although offering access to a whole media library, is similar to traditional offline and online video renting services, where customers pay a fee to rent/access a specific movie or TV show for a specific period of time and then have to return the physical copy or lose access to the digital copy, respectively [cf. 14]. Hence, MaaS can be seen as an extension of traditional media renting services.

\subsection{Psychological ownership}

In this section, we will first define psychological ownership (PO). Afterwards, we will introduce PO's two fundamental entities and point out their relationship. Next, we will present PO's commonly accepted antecedents, and also discuss situational and contextual influence factors of PO. Finally, we will present the findings of influential past research.

2.2.1. Definition. Etzioni [18] described property as an entity which could be perceived at two different levels: (1) the "real" object level where the object is tied to a set of rights and where scarcity is a unique characteristic of the actual object, and (2) the "mind"related object level that carries a symbolic, contextual or orientation-based view addressing the attitudinal focus of the individual, and often called psychological ownership (PO).

One of the most commonly used definitions of PO describes it as a "state in which individuals feel as though the target of ownership (material or immaterial in nature) or a piece of it is 'theirs"' $[39$, p. 299]. Thus, the question that can be answered by PO is 'What do I feel is mine?' [46].

To fully understand the notion of $\mathrm{PO}$, it is important to distinguish between $\mathrm{PO}$ and legal ownership (LO). LO has its origin in rules defined and recognized by society and protected by the legal system, whereas PO has its source in the perception of 
the individual [38] and thus can exist even in the absence of LO [21]. As a result, PO does not necessarily coincide with LO: On the one hand, a consumer might not feel that a legally acquired possession (e.g., a car, a house, clothing) belongs to them, because they never internalized the symbolic property of the object [31]; on the other hand, an individual can have a sense of ownership of an object even if they have no LO of it [e.g., 18, 21].

\subsubsection{The two fundamental entities of psychological} ownership and their relationship. The two fundamental entities of PO are individuals and targets. More specifically, ownership is generally experienced as a comprehensive person-object relation [38]. It reflects a relationship between an individual and a target, which is then perceived as having a close connection with the self [23]. Individuals can feel that a multitude of targets belong to them: Physical, (tangible) objects [13]; intangible objects like ideas or advice; and objects where the value for the individual is not the physical object itself, but rather the content "stored" on that object (e.g., memories) [11, 13]. In line with this, Ellis [17] developed several basic target categories, such as personal space, ingestibles, territory, domicile, other people (e.g., partners, offspring), tools, aesthetics, amusement, and associated objects. Overall, this emphasizes how manifold the number of potential targets is.

In addition to the targets themselves, the perception of ownership also depends on the target's attributes. Indeed, Pierce et al. [38] identified several attributes (attractiveness, accessibility, openness and manipulability) that have an impact on how strong an individual is able to develop feelings of ownership for a target $[36,38]$.

\subsubsection{Antecedents of psychological ownership.} There are three commonly-accepted distinct, but complementary, antecedents (also named routes, paths, or key factors) through which PO mainly emerges: (1) controlling the ownership target, (2) coming to intimately know the target, and (3) investing the self into the target.

First, Pierce et al. [39] emphasized the causality between an individual's degree of control over an object and the extent of PO for an object. Indeed, generally, ownership is the ability to use and to control the use of an object [42]. In other words, if someone believes they have control over a target (e.g., by the ability to control who has access to it), their sense of ownership will increase and thus the object will psychologically become a part of the individual [23].

Second, knowledge about an object and the feeling of ownership of that object are strongly connected.
When an individual gathers more and more information about an object, they accumulate intimate knowledge about it over time [6]. Since the individual develops a profound knowledge about the target, parameters such as the number of interactions and the duration of association with the object influence the individual's feeling of ownership of that object. In other words, there is a causality between the degree of intimate knowledge about a target and the extent of the individual's PO of it [39].

Finally, there is also a causal relationship between the degree of investment of the self into a target and the extent of PO for it. Durkheim [15] stated that the sense of ownership of an object someone has created is similar to the ownership towards themselves. Similarly, Rochberg-Halton [41] expressed that a sense of ownership is derived from the investment of the self into the object, which leads to the perception of the individual becoming one with the object. This investment of the self into the target can occur in many ways. In addition to, for example, time, skills, ideas, energy, care, concerns or responsibility, individuals also invest their values and identity, especially in the case of personal creations $[38,39]$.

\subsubsection{Situational and contextual influence factors of} psychological ownership. In addition to these three main antecedents of PO, Pierce et al. [38] also pointed out that further situational and contextual factors impact the extent to which PO is experienced by individuals. These factors are linked to the individual, such as changing motives over lifetime, personality traits, or changing relationships with the target (e.g., decoupling), which can lead to a reverse effect of PO through the reduction of cognitive and affective relationships towards the target. Pierce et al. [38] divided these contextual influence factors into structural factors (e.g., laws, rules, or hierarchy) and cultural factors (e.g., values, beliefs). Whereas structural factors mainly have an impact on the human motives and antecedents for PO, the cultural factors influence all of the elements of PO mentioned above, i.e., individuals, targets, the individual's perception of their needs, and PO's three main antecedents.

2.2.5. Past research. Over the past few decades, researchers and scholars from different areas (e.g., anthropologists, psychologists, social psychologists, philosophers) have examined PO from different angles, covering a broad spectrum of human beings' attitudinal and behavioral phenomena regarding possession, and have thus contributed to our current understanding of PO. Different PO constructs are available for different situations, such as individual PO (IPO) (this is mine) and collective PO (CPO) (this is ours) [36, 37]. 
One main focus of these studies was to study PO in the context of organizations and the relationship between employees within the organization [e.g., 4, 34, $35,36,39,45]$. In other areas, for example in consumer research and marketing [e.g., 28], the application of PO theory has increased steadily over the years with studies focusing on a range of different age groups, from young children [e.g., 22, 24] to elderly people [e.g., 11], and studies investigating the cultural impacts of PO [e.g., 22].

Today, studies focus in particular on PO in the context of the digital economy. More specifically, the changing business and revenue models of digital economy companies in terms of digital products and services and their implications for consumers' PO is an area of particular interest for researchers and practitioners alike [e.g., 7, 8, 9, 29, 43, 47]. However, no confirmatory studies based on quantitative data that we are aware of have yet evaluated the potentially different PO levels for content on physical media, media files, and free/paid MaaS. In the following section, we will outline our corresponding hypotheses.

\section{Research model}

As described above, three direct antecedents influence the degree of PO for a target: controlling the target, intimately knowing the target, and investing the self into the target [38]. The ability to control the target (a) by having direct physical control over it and (b) by controlling who else can have access to it is an especially salient characteristic of PO [21]. Moreover, accessibility and manipulability have been identified as important indirect influence factors of PO through the ability to control the target [38]. Also, the ability to touch a target has been identified as an additional factor that drives PO [33].

While physical media such as CDs and DVDs can be touched, services cannot be touched. Furthermore, whereas possessors of physical media have a direct physical control over the media, people using MaaS cannot control who else has access to the content they are consuming.

Moreover, whereas physical media have no restriction regarding the accessibility of the content over time, free and paid MaaS services are designed for the consumption of content at a specific moment without a long-term guarantee of access $[14,32] .^{2}$

Manipulability in the context of media content can be, for example, the availability of unlimited skips of

\footnotetext{
${ }^{2}$ For example, Taylor Swift pulled all her music from music as a service providers such as Spotify in 2014. As a result, people that listened to her music on the service before then no longer had access to it.
}

music tracks or to be able to decide what album to hear next. Whereas consumers have no restriction with regard to manipulability in physical media and on paid MaaS services, they regularly have such restrictions on free MaaS services.

While we do not see any differences between physical media and either kind of MaaS services regarding the intimate knowledge of the content (e.g., you can get into and begin to love Bob Dylan's work via all possible media), we see another difference regarding the investment of the self between physical media and content on MaaS services. Indeed, actively buying something and building a physical collection takes time. Furthermore, while buying physical media holds a long-term commitment to the target, just clicking on something to immediately consume it does not. In summary, we hypothesize that:

Psychological ownership is higher for content on physical media than for content on free MaaS services (H1a), or on paid MaaS services (H1b).

As described above, MaaS customers cannot control who else has access to the content they are consuming and, additionally, do not have any physical control over the content. In contrast, possessors of media files can at least control who else can have access to their files.

Moreover, like physical media, media files usually do not have any restrictions regarding the accessibility of the content over time. In contrast, as described above, free and paid MaaS services are designed for real-time consumption without a long-term guarantee of access [14, 32]. Additionally, free MaaS services have a lower level of manipulability than media files do.

Also, similar to physical media as described above, buying something and building a collection takes time. Furthermore, while buying content holds a long-term commitment to the target, just clicking on something to immediately consume it does not. In summary, we hypothesize that:

Psychological ownership is higher for content on digital files than for content on free MaaS services (H2a), or on paid MaaS services $(\boldsymbol{H} 2 \boldsymbol{b})$.

Finally, free and paid MaaS services differ with regard to their levels of manipulability and accessibility. Regarding manipulability, free MaaS services regularly hold restrictions, e.g., with regard to music track skips, etc., whereas paid MaaS services are usually not restricted in these ways. Similarly, free MaaS services are usually also restricted with regard to accessibility such as not being able to consume content 
while being offline or on mobile devices, whereas paid MaaS services usually do not have such restrictions. Additionally, we also believe that people are used to usually getting something in return when they pay for something, which further differentiates free MaaS services from paid MaaS services. We hypothesize that:

Psychological ownership is higher for content on paid MaaS services than for content on free MaaS services (H3).

\section{Research design}

\subsection{Experiment}

To test our hypotheses, we conducted an experiment in the context of music consumption. We chose to implement a between-subjects design [2] in which subjects were first randomly assigned to one of three experimental groups: music as a service, files from online media stores, and CDs. We believed that results from a within-subject design would have been severely flawed in our context, since subjects would not have been blind to condition (i.e., the different media) and, thus, memory effects, sponsorship effects, and sequence effects would have come up.

Then, every subject was asked about their individual levels of PO for the music album they most often listened to via the respective medium using the three-item PO scale of Peck and Shu [33]. All items were measured using a seven-point Likert-type scale ranging from "strongly disagree" to "strongly agree"; table 1 presents the items of our questionnaire).

Table 1. Items

\begin{tabular}{|l|l|}
\hline Construct (label) & Item (label) \\
\hline \multirow{4}{*}{$\begin{array}{l}\text { Psychological } \\
\text { ownership* (PO) }\end{array}$} & $\begin{array}{l}\text { I feel like this is my album (PO1) } \\
\text { ownership of this album (PO2) }\end{array}$ \\
\cline { 2 - 2 } & I feel like I own this album (PO3) \\
\hline
\end{tabular}

More specifically, in each group, we first asked the respondents whether they ever

- bought music albums as CDs,

- bought music albums as digital files from an online music store such as iTunes and the Google Play Store, or

- $\quad$ used a music streaming service such as Apple Music, Spotify, or Tidal, respectively.

If the respective respondents had not done the corresponding action, they were forwarded to the end of the questionnaire. In the case of the music as a service group, we further asked whether they had pay(ed) a fee for the music streaming service that they most often use $(d)$. Based on the answers, the group was later divided into two subgroups, i.e., free music as a service and paid music as a service. As a result, our final sample consisted not of three but four experimental groups.

Next, in order to prime our respondents to the respective kind of media, we first asked each respondent to please take a moment and think about the

- $\quad$ music albums that they had bought as a CD,

- music albums that they had bought as digital files from an online music store such as iTunes and the Google Play Store, or

- $\quad$ music streaming service that they most frequently $u s e(d)$, respectively.

Following this, we asked them to please take another moment and think about the music album they most often listen(ed) to

- that they had bought as a CD,

- that they had bought as digital files from an online music store, or

- on the music streaming service they most frequently use(d), respectively.

To complete the priming of our respondents to the respective media, we then asked them to name the artist and album title of the album they most often listen(ed) to

- that they had bought as a CD,

- that they had bought as digital files from an online music store, or

- on the music streaming service they most frequently use(d), respectively. ${ }^{3}$

Finally, we asked our respondents to read the following statements [see PO items in table 1] carefully and indicate their level of agreement with regard to the music album they named above.

\subsection{Data collection}

In May 2018, we recruited English-speaking respondents living in the US via Amazon Mechanical Turk over a period of three days. More specifically, speaking English and living in the US were obligatory

\footnotetext{
${ }^{3}$ A list of the artists and album titles named during the study are available on request from the authors.
} 
qualifications for participation in the study and we promised a reward of $1 \$$ per questionnaire. In this manner, we obtained 177 completed online questionnaires. However, we dropped 20 datasets from our sample: One respondent failed our attention check (in the questionnaire, we placed one item that asked the respondents to "please select agree") and was thus dropped from the analyses. Moreover, two respondents failed to name an album title, two respondents named two music as a service providers after selecting the "other" category (rather than only one), and 15 respondents had never used any music as a service (9), files (4), or CDs (2), respectively, and thus were all dropped from further analyses. As a result, we had a final sample size of 157 subjects (36 datasets in the free music as a service group, 39 datasets in the paid music as a service group, 41 datasets in the file group, 41 datasets in the $\mathrm{CD}$ group).
Table 2 presents the demographics and controls of our complete sample as well as of our four experimental groups including gender, age, and current profession. Our sample consisted mostly of people who were currently employed (89.2 percent) and relatively young (mean: 35.54; std. dev.: 8.64). Furthermore, our sample consisted of more men (59.2 percent). According to the results of two one-way ANOVAs and one likelihood-ratio chi-square-tests, no significant difference was detected across groups in gender, age, and current profession (see table 2). This suggests a successful random assignment of subjects to our experimental groups and supports the claim that the experimental groups did not differ with regard to these important covariates. This means we could rule out structural group differences as being the cause of any differences found in our dependent variable between groups.

Table 2. Demographics and controls

\begin{tabular}{|c|c|c|c|c|c|c|c|c|}
\hline & & & & & & & $\begin{array}{l}\text { ANOVA } \\
\text { ratio chi }\end{array}$ & $\begin{array}{l}\text { elihood- } \\
\text { are-test }\end{array}$ \\
\hline & Range & $\begin{array}{c}\text { Free music as a } \\
\text { service (FMaaS) } \\
\mathrm{N}=36\end{array}$ & $\begin{array}{c}\text { Paid music as a } \\
\text { service (PMaaS) } \\
\mathrm{N}=39\end{array}$ & $\begin{array}{c}\text { File } \\
\text { (F) } \\
\mathrm{N}=41 \\
\end{array}$ & $\begin{array}{c}\text { CD } \\
\mathrm{N}=41\end{array}$ & \begin{tabular}{|c|} 
Complete \\
Sample \\
$\mathrm{N}=157$ \\
\end{tabular} & $\mathrm{~F} / \chi^{2}$ & $\mathbf{p}$ \\
\hline $\begin{array}{l}\text { Age } \\
\text { Mean } \\
\text { Standard deviation }\end{array}$ & $23-65$ & $\begin{array}{c}34.25 \\
5.89\end{array}$ & $\begin{array}{l}35.26 \\
9.164\end{array}$ & $\begin{array}{l}35.83 \\
8.672\end{array}$ & $\begin{array}{c}36,63 \\
10.141\end{array}$ & $\begin{array}{c}35.54 \\
8.64\end{array}$ & $.511^{\mathrm{a}}$ & $.675^{\mathrm{a}}$ \\
\hline Percentage of females & $0-100$ & 36.1 & 38.5 & 41.5 & 46.3 & 40.8 & $.309^{\mathrm{a}}$ & $.819^{\mathrm{a}}$ \\
\hline $\begin{array}{l}\text { Current profession } \\
\text { Pupil } \\
\text { Apprentice } \\
\text { Student } \\
\text { Retired } \\
\text { Employed } \\
\text { Unemployed } \\
\text { Other } \\
\end{array}$ & - & $\begin{array}{c}0 \\
0 \\
0 \\
0 \\
32 \\
1 \\
3 \\
\end{array}$ & $\begin{array}{c}0 \\
0 \\
0 \\
0 \\
35 \\
3 \\
1 \\
\end{array}$ & $\begin{array}{c}0 \\
1 \\
0 \\
0 \\
39 \\
0 \\
1 \\
\end{array}$ & $\begin{array}{c}0 \\
0 \\
1 \\
1 \\
34 \\
3 \\
2 \\
\end{array}$ & $\begin{array}{c}0 \\
1 \\
1 \\
1 \\
140 \\
7 \\
7\end{array}$ & $15.50^{\mathrm{b}}$ & $.416^{\mathrm{b}}$ \\
\hline
\end{tabular}

Table 3. Item and construct descriptives

\begin{tabular}{|c|c|c|c|c|c|c|c|c|c|c|c|c|c|c|c|}
\hline \multirow{2}{*}{$\begin{array}{l}\text { Construct } \\
\text { Item }\end{array}$} & \multicolumn{3}{|c|}{ FMaaS } & \multicolumn{3}{|c|}{ PMaaS } & \multicolumn{3}{|c|}{ File (F) } & \multicolumn{3}{|c|}{ CD } & \multicolumn{3}{|c|}{ Complete sample } \\
\hline & M & $\mathrm{SD}$ & Mdn & $\mathrm{M}$ & $\mathrm{SD}$ & Mdn & M & $\mathrm{SD}$ & Mdn & M & SD & Mdn & $\mathrm{M}$ & SD & $\mathrm{Mdn}$ \\
\hline PO* & 3.93 & 2.12 & 4.83 & 5.18 & 1.66 & 6.00 & 5.89 & 1.14 & 6.00 & 6.19 & .90 & 6.33 & 5.34 & 1.72 & 6.00 \\
\hline PO1 & 3.94 & 2.03 & 4.50 & 5.28 & 1.73 & 6.00 & 5.85 & 1.28 & 6.00 & 6.00 & .95 & 6.00 & 5.31 & 1.71 & 6.00 \\
\hline $\mathrm{PO} 2$ & 3.94 & 2.15 & 5.00 & 5.10 & 1.70 & 6.00 & 5.90 & 1.22 & 6.00 & 6.27 & .98 & 6.00 & 5.35 & 1.77 & 6.00 \\
\hline PO3 & 3.89 & 2.30 & 4.50 & 5.15 & 1.80 & 6.00 & 5.93 & 1.25 & 6.00 & 6.29 & 1.01 & 7.00 & 5.36 & 1.86 & 6.00 \\
\hline
\end{tabular}

\section{Results}

\subsection{Descriptives}

Table 3 presents the descriptives per questionnaire item (mean and SD) and the average composite score for PO. We also examined the distribution properties of our four groups using Shapiro-Wilk-tests. All intra- group distributions were non-normally distributed $\left(\mathrm{W}_{\text {FMaas }}=.881, \mathrm{p}=.001 ; \quad \mathrm{W}_{\text {PMaaS }}=.862, \mathrm{p}=.000 ;\right.$ $\left.\mathrm{W}_{\mathrm{F}}=.770, \mathrm{p}=.000 ; \mathrm{W}_{\mathrm{CD}}=.788, \mathrm{p}=.000\right)$.

\subsection{Hypothesis testing}

Due to the non-normality of our data as described above, we used the non-parametric Mann-Whitney U 
test to test for group differences [e.g., 19]. Table 4 presents the results.

Table 4. Mann-Whitney U tests

\begin{tabular}{|l|l|c|c|c|c|}
\hline Construct & Comparison & Hypothesis & $\mathbf{z}$ & $\mathbf{p}$ & $\mathbf{r}$ \\
\hline \multirow{4}{*}{ PO } & CD v FMaaS & H1a & -5.108 & .000 & -.582 \\
\cline { 2 - 6 } & CD v PMaaS & H1b & -2.765 & .003 & -.309 \\
\cline { 2 - 6 } & F v FMaaS & H2a & -4.376 & .000 & -.499 \\
\cline { 2 - 6 } & F v PMaaS & H2b & -1.751 & .040 & -.196 \\
\cline { 2 - 7 } & FMaaS v PMaaS & H3 & -.286 & .002 & -.330 \\
\hline
\end{tabular}

When we compared the levels of PO of the group that evaluated the album they listened to most frequently on free music as a service services with the group that evaluated the album they listened to most frequently on paid music as a service services, we found a significant difference with a medium effect size $(\mathrm{z}=-.286, \quad \mathrm{p}=.002, \quad \mathrm{r}=-.330), \quad$ supporting hypothesis 3. Likewise, we found significant differences regarding the PO level between the file group and both the free music as a service group $(\mathrm{z}=-$ 4.376, $\mathrm{p}=.000, \mathrm{r}=-.499$ ) and the paid music as a service group $(\mathrm{z}=-1.751, \mathrm{p}=.040, \mathrm{r}=-.196)$, accounting for a medium to large effect size and a small effect size, respectively, and supporting hypotheses $2 \mathrm{a} / 2 \mathrm{~b}$. We also found significant differences regarding the PO levels between the $C D$ group and both the free music as a service group $(\mathrm{z}=-$ $5.108, \mathrm{p}=.000, \mathrm{r}=-.582)$ and the paid music as a service group $(\mathrm{z}=-2.765, \mathrm{p}=.003, \mathrm{r}=-.309)$, accounting for a large effect size and a medium effect size, respectively, and supporting hypotheses $1 \mathrm{a} / 1 \mathrm{~b}$.

\section{Conclusion}

In this article, we studied whether MaaS services, and in particular the ones that are free of charge cause customers to feel a lower degree of PO for the provided content than for content provided via physical media and media files. Based on an experiment with 157 subjects and their consumption of music, our study suggests that MaaS services and in particular the ones that are free of charge indeed cause customers to feel a lower degree of PO for the provided content than for content provided via physical media and media files.

These findings hold important practical implications. Since PO is known to positively influence loyalty, willingness to pay, customer satisfaction, word-of-mouth, and service valuation [1, $20,25,28,45,47]$, the entertainment industry and service providers need to address MaaS' lower degree of PO, not least because of their growing dependence on its revenues. Moreover, our findings suggest that the entertainment industry does not need to decide on one particular distribution model to use: Rather, all can coexist. Indeed, the findings suggest that due to advantages with regard to $\mathrm{PO}$, a coexistence of physical media and media files with MaaS might be the way to go for the entertainment industry [cf. 16, 32]. An additional strategy might also be to combine MaaS with traditional media file sales, i.e., by enabling subscribers to buy content of the catalogue that will remain in their library even when they cancel the subscription.

Though our findings hold important practical implications, our study has some limitations. First, our empirical study was only based on one kind of MaaS: music as a service. Hence, our findings might not hold true for other types of content, i.e., movies and TV shows. Moreover, our sample individuals were relatively young (mean: 35.54; std. dev.: 8.64) and were English-speaking people who are currently employed and living in the US (89.2 percent). Additionally, all participants were using Amazon Mechanical Turk as one source of personal income. Thus, our results might not hold true for people from other age groups, countries, or social groups.

As a next step, we plan to expand our research and address its limitations. More specifically, we would like to roll out our survey to other countries and in particular survey people that are older and younger than those in our sample. Moreover, we also plan to replicate our findings in the contexts of video as a service, e-book as a service, and video game as a service. Finally, we want to examine which of MaaS' attributes (accessibility and manipulability) and also which known antecedents of PO (controlling the target, coming to intimately know the target, and investing the self into the target) are the most important factors driving actual PO of content in the context of MaaS. In doing so, we hope to be able to provide specific guidance to the entertainment industry as well as service providers as to how they can improve their MaaS services by consolidating their strong revenue driver.

\section{References}

[1] V.S. Asatryan, and H. Oh, "Psychological Ownership Theory: An Exploratory Application in the Restaurant Industry", Journal of Hospitality \& Tourism Research 32 (3), 2008, pp. 363-386.

[2] C. Atzmüller, and P.M. Steiner, "Experimental Vignette Studies in Survey Research", Methodology 6 (3), 2010, pp. $128-138$.

[3] D. Austerberry, The Technology of Video and Audio Streaming, Focal Press, Burlington, MA, 2013. 
[4] J.B. Avey, B.J. Avolio, C.D. Crossley, and F. Luthans, "Psychological Ownership: Theoretical Extensions, Measurement and Relation to Work Outcomes", Journal of Organizational Behavior 30 (2), 2009, pp. 173-191.

[5] F. Bardhi, and G.M. Eckhardt, "Access-Based Consumption: The Case of Car Sharing", Journal of Consumer Research 39 (4), 2012, pp. 881-898.

[6] J.K. Beggan, and E.M. Brown, "Association as a Psychological Justification for Ownership", The Journal of Psychology 128 (4), 1994, pp. 365-380.

[7] R.W. Belk, "Extended Self and the Digital World", Current Opinion in Psychology 10, 2016, pp. 50-54.

[8] R.W. Belk, "Extended Self in a Digital World", Journal of Consumer Research 40 (3), 2013, pp. 477-500.

[9] R.W. Belk, "You Are What You Can Access: Sharing and Collaborative Consumption Online", Journal of Business Research 67 (8), 2014, pp. 1595-1600.

[10] P. Belleflamme, and M. Peitz, Digital Piracy, in J. Backhaus (eds.), Encyclopedia of Law and Economics, Springer, New York, NY, 2014, pp. 1-8.

[11] F. Cram, and H. Paton, "Personal Possessions and SelfIdentity: The Experiences of Elderly Women in Three Residential Settings", Australasian Journal on Ageing 12 (1), 1993, pp. 19-24.

[12] O. Dictionaries, Streaming, http://en.oxforddictionarie s.com/definition/streaming, 2018 (Accessed: 2018-05-14).

[13] H. Dittmar, The Social Psychology of Material Possessions: To Have Is to Be, Harlow, UK, 1992.

[14] J. Doerr, A. Benlian, J. Vetter, and T. Hess, "Pricing of Content Services - an Empirical Investigation of Music as a Service", AMCIS 2010 Proceedings.

[15] E. Durkheim, Professional Ethics and Civic Morals, Routledge, London, UK, 1957.

[16] A. Elberse, "Bye-Bye Bundles: The Unbundling of Music in Digital Channels", Journal of Marketing 74 (3), 2010, pp. 107-123.

[17] L. Ellis, "On the Rudiments of Possessions and Property", Social Science Information 24 (1), 1985, pp. 113143.

[18] A. Etzioni, "The Socio-Economics of Property", Journal of Social Behavior and Personality 6 (6), 1991, pp. 465-468.

[19] A. Field, Discovering Statistics Using SPSS, Sage, Thousand Oaks, CA, 2009.
[20] C. Fuchs, E. Prandelli, and M. Schreier, "The Psychological Effects of Empowerment Strategies on Consumers' Product Demand", Journal of Marketing 74 (1), 2010, pp. 65-79.

[21] L. Furby, "The Origins and Early Development of Possessive Behavior", Political Psychology 2 (1), 1980, pp. $30-42$.

[22] L. Furby, "Possession in Humans: An Exploratory Study of Its Meaning and Motivation", Social Behavior and Personality: An international Journal 6 (1), 1978, pp. 49-65.

[23] L. Furby, "Possessions: Toward a Theory of Their Meaning and Function Throughout the Life Cycle", LifeSpan Development and Behavior 1, 1978, pp. 297-336.

[24] L. Furby, "Understanding the Psychology of Possession and Ownership: A Personal Memoir and an Appraisal of Our Progress", Journal of Social Behavior and Personality 6 (6), 1991, pp. 457-463.

[25] J.F. Hair, K. Barth, D. Neubert, and M. Sarstedt, "Examining the Role of Psychological Ownership and Feedback in Customer Empowerment Strategies", Journal of Creating Value 2 (2), 2016, pp. 194-210.

[26] IFPI, Global Music Report, International Federation of the Phonographic Industry, London, UK, 2018.

[27] IFPI, Global Music Report, International Federation of the Phonographic Industry, London, UK, 2016.

[28] I. Jussila, A. Tarkiainen, M. Sarstedt, and J.F. Hair, "Individual Psychological Ownership: Concepts, Evidence, and Implications for Research in Marketing", Journal of Marketing Theory and Practice 23 (2), 2015, pp. 121-139.

[29] E. Karahanna, S.X. Xu, and N. Zhang, "Psychological Ownership Motivation and Use of Social Media", Journal of Marketing Theory and Practice 23 (2), 2015, pp. 185-207.

[30] Y. Liu, Y. Guo, and C. Liang, "A Survey on Peer-toPeer Video Streaming Systems", Peer-to-Peer Networking and Applications 1 (1), 2008, pp. 18-28.

[31] G. McCracken, "Culture and Consumption: A Theoretical Account of the Structure and Movement of the Cultural Meaning of Consumer Goods", Journal of Consumer Research 13 (1), 1986, pp. 71-84.

[32] G.D. Nguyen, S. Dejean, and F. Moreau, "On the Complementarity between Online and Offline Music Consumption: The Case of Free Streaming", Journal of Cultural Economics 38 (4), 2014, pp. 315-330.

[33] J. Peck, and S.B. Shu, "The Effect of Mere Touch on Perceived Ownership", Journal of Consumer Research 36 (3), 2009, pp. 434-447. 
[34] H. Peng, and J. Pierce, "Job-and Organization-Based Psychological Ownership: Relationship and Outcomes", Journal of Managerial Psychology 30 (2), 2015, pp. 151-168.

[35] J.L. Pierce, and D.G. Gardner, "Self-Esteem within the Work and Organizational Context: A Review of the Organization-Based Self-Esteem Literature", Journal of Management 30 (5), 2004, pp. 591-622.

[36] J.L. Pierce, and I. Jussila, "Collective Psychological Ownership within the Work and Organizational Context: Construct Introduction and Elaboration", Journal of Organizational Behavior 31 (6), 2010, pp. 810-834.

[37] J.L. Pierce, I. Jussila, and D. Li, "Development and Validation of an Instrument for Assessing Collective Psychological Ownership in Organizational Field Settings", Journal of Management \& Organization, 2017, pp. 1-17.

[38] J.L. Pierce, T. Kostova, and K.T. Dirks, "The State of Psychological Ownership: Integrating and Extending a Century of Research", Review of General Psychology 7 (1), 2003, pp. 84-107.

[39] J.L. Pierce, T. Kostova, and K.T. Dirks, "Toward a Theory of Psychological Ownership in Organizations", Academy of Management Review 26 (2), 2001, pp. 298-310.

[40] J. Rifkin, The Age of Access: The New Culture of Hypercapitalism, Where All of Life Is a Paid-for Experience, Jeremy P. Tarcher/Putnam, New York, NY, 2000.

[41] E. Rochberg-Halton, Cultural Signs and Urban Adaptation: The Meaning of Cherished Household Possessions. Ph.D. Dissertation, University of Chicago, 1979.
[42] F.W. Rudmin, and J.W. Berry, "Semantics of Ownership: A Free-Recall Study of Property", The Psychological Record 37 (2), 1987, pp. 257-268.

[43] G. Sinclair, and J. Tinson, "Psychological Ownership and Music Streaming Consumption", Journal of Business Research 71, 2017, pp. 1-9.

[44] Statista, Most Number of Visits to Media Piracy Sites Worldwide in 2017, by Country (in Billions), http://www.sta tista.com/statistics/786046/media-piracy-site-visits-by-count ry, 2018 (Accessed: 2018-06-03).

[45] L. Van Dyne, and J.L. Pierce, "Psychological Ownership and Feelings of Possession: Three Field Studies Predicting Employee Attitudes and Organizational Citizenship Behavior", Journal of Organizational Behavior 25 (4), 2004, pp. 439-459.

[46] B. Wilpert, Property, Ownership, and Participation: On the Growing Contradictions between Legal and Psychological Concepts, in R.A. Russell and V.A. Rus (eds.), International Handbook of Participation in Organizations: For the Study of Organizational Democracy, Co-Operation, and Self Management, Oxford University Press, Oxford, UK, 1991, pp. 149-164.

[47] Q. Zhao, C.-D. Chen, and J.-L. Wang, "The Effects of Psychological Ownership and TAM on Social Media Loyalty: An Integrated Model", Telematics and Informatics 33 (4), 2016, pp. 959-972. 